\title{
Angiotensin-converting enzyme genotype and the ventilatory response to exertional hypoxia
}

\author{
S. Patel*, D.R. Woods", N.J. Macleod*, A. Brown`, K.R. Patel ${ }^{\Uparrow}$, H.E. Montgomery ${ }^{\#}$, A.J. Peacock*
}

Angiotensin-converting enzyme genotype and the ventilatory response to exertional hypoxia. S. Patel, D.R. Woods, N.J. Macleod, A. Brown, K.R. Patel, H.E. Montgomery, A.J. Peacock. (C)ERS Journals Ltd 2003.

ABSTRACT: The "insertion" (I) rather than "deletion" (D) variant of the human angiotensin-converting enzyme (ACE) gene is associated with both lower tissue ACE activity and elite performance at high altitude. Three genotypes, II, ID and DD, are thus represented in the population. The authors examined whether an improved ventilatory response to hypoxic exercise may contribute to this effect.

Subjects $(n=60 ; 37$ male, mean \pm SEM age $23.6 \pm 0.6$ yrs, 14 II, 30 ID, 16 DD) underwent incremental cardiopulmonary exercise testing to establish maximal oxygen uptake and ventilatory threshold (VT). Four hours later, subjects exercised for 6 mins at $50 \%$ of the workload at VT. The protocol was repeated 15 mins later while breathing $12.5 \pm 0.5 \%$ oxygen in nitrogen.

All subject characteristics were independent of genotype, as were data during normoxic exercise. However, the hypoxia-induced rise in minute ventilation was significantly greater among those of II genotype $(39.6 \pm 4.1 \%$ versus $27.9 \pm 2.0 \%$ versus $\mathbf{2 8 . 4} \pm \mathbf{2 . 2} \%$ for II versus ID versus DD, respectively). These data are supported by a significantly greater decrease in end tidal carbon dioxide (consistent with an increase in alveolar ventilation) among those homozygous for the I allele (II $-18.7 \pm 1.3 \%$, ID $-15.7 \pm 0.4 \%$, DD $-15.1 \% \pm 1.1)$.

The ventilatory response to hypoxic exercise is influenced by angiotensin-converting enzyme genotype. Potential implications concern high altitude performance and the pathogenesis and management of hypoxic lung disease.

Eur Respir J 2003; 22: 755-760.
*Scottish Pulmonary Vascular Unit, Western Infirmary, Dumbarton Road, and ${ }^{\top}$ Dept of Respiratory Medicine, Gartnavel General Hospital, Great Western Road, Glasgow, and ${ }^{\#}$ British Heart Foundation Centre for Cardiovascular Genetics, Rayne Institute, 5 University Street, London, UK.

Correspondence: A. J. Peacock, Scottish Pulmonary Vascular Unit, Level 8, Western Infirmary, Dumbarton Road, Glasgow, G11 6NT, UK.

Fax: 441412116334

E-mail: apeacock@udcf.gla.ac.uk

Keywords: Altitude, angiotensin-coverting enzyme, exercise, hypoxia, polymorphism, ventilation

Received: September 172002

Accepted after revision: July 92003

The funding for this study was from Dept of Respiratory Medicine research funds. H.E. Montgomery is funded by the British Heart Foundation.
Ascent to high altitude requires exertion in a progressively severe hypobaric hypoxic environment. Although genetic differences may contribute greatly to the diversity in performance at altitude [1], to date, only one locus of importance has been identified.

Circulating angiotensin-converting enzyme (ACE) exerts a tonic regulatory function in circulatory homeostasis, through the synthesis of vasoconstrictor angiotensin II (AngII), which also drives aldosterone synthesis, and the degradation of vasodilator kinins. Meanwhile, ACE is also expressed in a variety of human tissue, including myocardium [2], skeletal muscle [3], brain [4] and lung [5] where it may serve a variety of different functions. A polymorphic variant of the human ACE gene has been identified, in which the insertion (I), rather than deletion (D) variant, is associated with lower circulating [6] and tissue [2] ACE activity.

An excess frequency of the ACE I allele has been noted among elite endurance athletes [7-9], which may be partly explained by a genotype-dependent improvement in skeletal muscle mechanical efficiency with training [10]. However, an even greater excess among high-altitude mountaineers suggests that here additional mechanisms are likely to be at work [11]. A genotype-dependent modulation in respiratory drive at altitude may be one such mechanism. At altitude, diminished alveolar oxygen tensions lead to lower arterial oxygen tensions. However, the fall in oxygen availability with altitude is sensed by carotid bodies that contain hypoxia-sensitive AngII type-1 (AT1) receptors [12, 13], driving an increase in minute ventilation $\left(V^{\prime} \mathrm{E}\right)$. This compensatory increase in alveolar ventilation (the hypoxic ventilatory response; HVR), helps sustain arterial oxygen saturations $\left(\mathrm{Sa}_{\mathrm{a}} \mathrm{O}_{2}\right)$ and tissue oxygen delivery. The marked interindividual variations in HVR [14] are likely to have a strong genetic component [15-17], to which polymorphic variation in genes of the reninangiotensin system (RAS) may thus substantially contribute.

Therefore, the hypothesis that the ACE I/D polymorphism is associated with differences in the ventilatory response to hypoxic exercise was tested.

\section{Methods}

The study had local ethics committee approval. All subjects gave informed consent. Investigators were blinded to genotype until all the data had been collected.

\section{Subjects}

Caucasian student volunteers $(n=60 ;$ mean \pm SD age $23.6 \pm$ $4.7 \mathrm{yrs}$, height $177.4 \pm 8.5 \mathrm{~cm}$, weight $73.5 \pm 11.0 \mathrm{~kg}$, maximal oxygen uptake $\left.\left(V_{2}, \max \right) 51.1 \pm 11.7 \mathrm{~L} \cdot \mathrm{min}^{-1}\right)$ from the University of Glasgow were studied. All had been residing below $2,000 \mathrm{~m}$ for $>2$ months. They were nonsedentary, taking part in social noncompetitive recreational activities. All were free of significant cardiorespiratory or musculoskeletal disease, 
were nonsmokers, had normal lung function and were taking no regular medication.

\section{Exercise protocol}

All volunteers abstained from alcohol, caffeine or strenuous exercise for $12 \mathrm{~h}$ prior to exercise testing. Incremental cardiopulmonary exercise testing established $V_{\mathrm{O}_{2}}$, max and ventilatory threshold (VT). Four hours later, 5 min rest was followed by a normoxic exercise phase $(6 \mathrm{mins})$ at $50 \%$ of the workload at VT. The protocol was repeated 15 mins later while breathing $12.5 \pm 0.5 \% \mathrm{O}_{2}$ in nitrogen $\left(\mathrm{N}_{2}\right)$. Over the last $90 \mathrm{~s}$ of each phase, breath-by-breath measurements were averaged and $V^{\prime} \mathrm{E}$ calculated from tidal volume $(V \mathrm{~T})$ and respiratory rate (RR). Poikilocapnic rather than the isocapnic ventilatory response to hypoxia was studied because this more closely mimicked the environmental exposure that would be experienced at altitude on the mountainside. Subjects exercised to the point where leg fatigue prevented any further progression through the ramp protocol, and all surpassed maximal predicted heart rate. Subjects were deemed to have exercised maximally when the slope of oxygen uptake $\left(\mathrm{VO}_{2}\right)$ plotted against workload was seen to plateau.

\section{Technical methodology}

All cardiopulmonary exercise testing was by breath-bybreath ventilatory gas analysis on a commercially available metabolic cart (Sensormedics V2900; Sensormedics, Yorba Linda, CA, USA). Prior to each test the mass flow sensor was calibrated using a standard 3-L syringe. Two-point gas sensor calibration (Paramagnetic oxygen sensor and infrared carbon dioxide $\left(\mathrm{CO}_{2}\right)$ analyser) was performed according to manufacturer's instructions prior to each test using standard calibration gases $\left(16 \% \mathrm{O}_{2}: 4 \% \mathrm{CO}_{2}\right.$ :balance $\mathrm{N}_{2}$ and $24 \%$ $\mathrm{O}_{2}$ :balance $\mathrm{N}_{2}$; Sensormedics). Twelve-lead electrocardiogram was recorded before and during all tests (MAX-1; Marquette electronics, Milwaukee, WI, USA). Subjects were fitted with noseclips and full-face masks with disposable gel seals (Universal seal; Hans Rudolph Inc., Kansas city, MO, USA), and exercised on an electronically braked cycle ergometer (Ergoline 900; Ergometrics, Bitz, Germany) at a constant cadence of 60 revolutions $\cdot \mathrm{min}^{-1}$. $\mathrm{Sa}, \mathrm{O}_{2}$ was measured using transcutaneous pulse oximetry (Ohmeda Biox 3700; Ohmeda, Boulder, $\mathrm{CO}$, USA.). $\mathrm{VO}_{2}$, carbon dioxide production $\left(V \mathrm{CO}_{2}\right)$, end-tidal carbon dioxide $\left(\mathrm{ETCO}_{2}\right), V \mathrm{~T}$ and $\mathrm{RR}$ were also measured. $V^{\prime} \mathrm{E}$ was calculated.

Cylinder air was diluted with $\mathrm{N}_{2}$ (Linde Gases Ltd, Aberdeen, UK) to provide a hypoxic mixture of $12.5 \pm 0.5 \%$ $\mathrm{O}_{2}$. Gas mixtures were administered from a 1,000-L Douglas bag (Hans Rudolph Inc.) via a three-way tap (2700 series; Hans Rudolph Inc.). This was connected by $35-\mathrm{mm}$ tubing to a nonrebreathe valve (2100 series; Hans Rudolph Inc.), the mass flow sensor, and then to the subjects' face mask. Ventilatory variables were calculated from measurements of gas volume flow from this sensor by the software provided with metabolic cart. The circuit introduced an increased dead space; this was taken into account by amending the value for dead space used by the software for ventilatory calculations. Finally, in order to ensure that individuals had reached steady state exercise and had not crossed the VT, means of threebreath measurements were used to generate a line of best fit for breath-by-breath plot. Steady state was then determined electronically and confirmed visually (as a "flat line"). The final $90 \mathrm{~s}$ of the test were then examined for increases in $\mathrm{VO}_{2}$ or $V \mathrm{CO}_{2}$ and used in data acquisition. Repeatability of the steady state protocol was validated in five subjects, whose data on repetitive testing were within a maximum of $10 \%$ of those originally recorded. The median coefficients of variation for $V \mathrm{O}_{2}$ and $V^{\prime} \mathrm{E}$ for these five subjects were $4.4 \%$ (range $1.1-7.4 \%$ ) and $5.3 \%$ (range $0.4-5.6 \%$ ), respectively.

\section{Genotyping}

Deoxyribonucleic acid was extracted from mouthwash samples as described previously [18] with the ACE genotype determined using a three-primer method [19] yielding amplification products of 65 base pairs (I allele) and 84 base pairs (D allele). These were separated by electrophoresis on a $7.5 \%$ polyacrylamide gel and visualised using ethidium bromide. All genotyping was performed by experienced staff blind to subject data.

\section{Statistical analysis}

Differences in measured variables under hypoxic conditions were expressed as a percentage of those under normoxic conditions. Responses in each variable were tested for normality for each genetic group. Data for homozygote groups were compared by analysis of variance and data across genotypes by Chi-squared analysis for linear trend. Data are expressed as mean \pm SEM.

\section{Results}

$\mathrm{VO}_{2}$ at rest, for a given work rate and during exercise were similar under normoxic and hypoxic conditions (change at rest $-0.4 \pm 2.1 \%, \mathrm{p}=0.8$; exercise $0.7 \pm 1.0 \%, \mathrm{p}=0.9$ ), in keeping with Haldane's criteria.

Subject characteristics (table 1) were independent of genotype (14 II, 30 ID, 16 DD, consistent with HardyWeinberg equilibrium), as were data during normoxic exercise $\left(V^{\prime} \mathrm{E} 34.9 \pm 0.9 \mathrm{~L} \cdot \mathrm{min}^{-1}\right)$. However, the hypoxia-induced rise in $V^{\prime} \mathrm{E}$ was strongly related to genotype $(39.6 \pm 4.1 \%$ versus $27.9 \pm 2.0 \%$ versus $28.4 \pm 2.2 \%$, for II versus ID versus DD, respectively; $\mathrm{p}=0.008$ for linear trend, $\mathrm{p}<0.02$ for II versus $\mathrm{DD}, \mathrm{p}<0.002$ for II versus presence of $\mathrm{D}$ allele (D+; $28.4 \pm 2.2 \%$ ); fig. 1). These data are supported by a significantly greater decrease in $\mathrm{ETCO}_{2}$ (consistent with an increase in alveolar ventilation) among those homozygous for the I allele (fig. $2 \mathrm{a}$ shows II $-18.7 \pm 1.3 \%$, ID $-15.7 \pm 0.4 \%$, DD $-15.1 \pm 1.1 \%, \mathrm{p}<0.05$ for II versus $\mathrm{DD}$; fig. $2 \mathrm{~b}$ shows II versus $\mathrm{D}+-15.2 \pm 0.6 \%, \mathrm{p}<0.02$ ). However, there were no significant differences in $\mathrm{Sa}, \mathrm{O}_{2}$ during exercise between genotypes (fig. 3

Table 1.-Genotype and physical characteristics of subject groups

\begin{tabular}{lccc}
\hline & II & ID & DD \\
\hline Subjects n & 14 & 30 & 16 \\
Age yrs & $23.6 \pm 4.7$ & $23.2 \pm 4.3$ & $24.7 \pm 6.1$ \\
Height cm & $178.3 \pm 8.3$ & $177.1 \pm 8.14$ & $178.5 \pm 7.9$ \\
Weight kg & $71.9 \pm 8.3$ & $73.4 \pm 11.7$ & $75.9 \pm 10.4$ \\
$V \mathrm{O}_{2}, \mathrm{max} \mathrm{mL} \cdot \mathrm{kg}^{-1}$ & $55.9 \pm 13.2$ & $49.3 \pm 11.0$ & $52.8 \pm 11.6$ \\
$V \mathrm{O}_{2}$ at $\mathrm{VT} \mathrm{mL} \cdot \mathrm{kg}^{-1}$ & $33.9 \pm 7.6$ & $29.3 \pm 9.1$ & $32.1 \pm 10.4$ \\
\hline
\end{tabular}

Data are presented as mean $\pm \mathrm{SD}$ unless otherwise stated. $V \mathrm{O}_{2}$, max maximal oxygen uptake; $V \mathrm{O}_{2}$ : oxygen uptake; $V T$ : ventilatory threshold. Groups were physically similar and there was no demonstrable statistically significant difference between homozygote groups. 


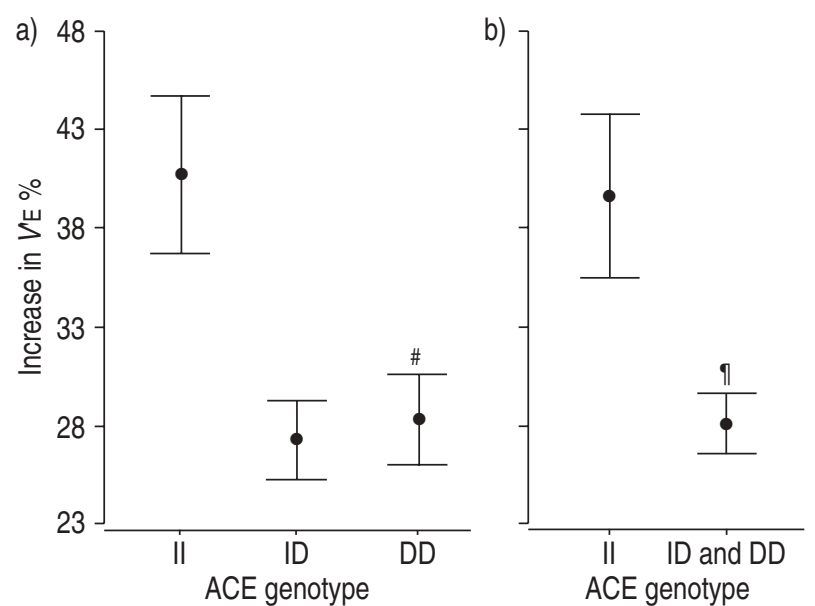

Fig. 1. - a) Demonstrates the mean \pm SEM per cent increases in minute ventilation $\left(V^{\prime} \mathrm{E}\right)$ during exercise from the three angiotensin-converting enzyme (ACE) genotype groups (insertion homozygote (II), heterozygote (ID), deletion homozygote (DD)) as the subjects progressed from normoxia to hypoxia. \#: $\mathrm{p}<0.02$ versus II. b) compares the mean \pm SEM per cent increases in $V^{\prime} E$ during exercise between II and deletion allele (ID and DD). : $\mathrm{p}=0.002$ versus II.

shows II $-24.5 \pm 2.1 \%$, ID $-26.3 \pm 1.0 \%$, DD $-25.9 \pm 2.1 \%$ ). Data are presented fully in tables 2 and 3.

\section{Discussion}

The authors have demonstrated that the ventilatory response to hypoxic exercise is greater amongst those of ACE II genotype.

Low ACE activity, as marked by the ACE I allele, is associated with elite performance at high altitude [10]. An enhanced respiratory response to hypoxic exercise may contribute to this phenomenon through the associated minimisation of pulmonary vasoconstriction and maximisation of alveolar-capillary diffusion gradient.
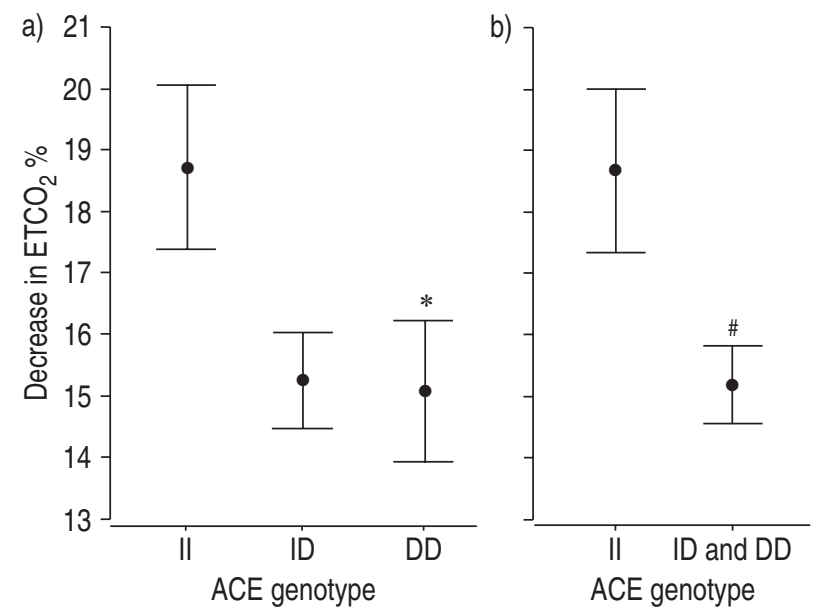

Fig. 2. - Demonstrates the mean \pm SEM per cent decreases in end-tidal carbon dioxide $\left(\mathrm{ETCO}_{2}\right)$ during exercise from the three angiotensinconverting enzyme (ACE) genotype groups (insertion homozygote (II), heterozygote (ID), deletion homozygote (DD)) as the subjects progressed from normoxia to hypoxia. *: $\mathrm{p}<0.05$ versus II. b) compares the per cent decreases in $\mathrm{ETCO}_{2}$ during exercise between II and deletion allele (ID and DD). ${ }^{\#}$ : $\mathrm{p}<0.02$ versus II.

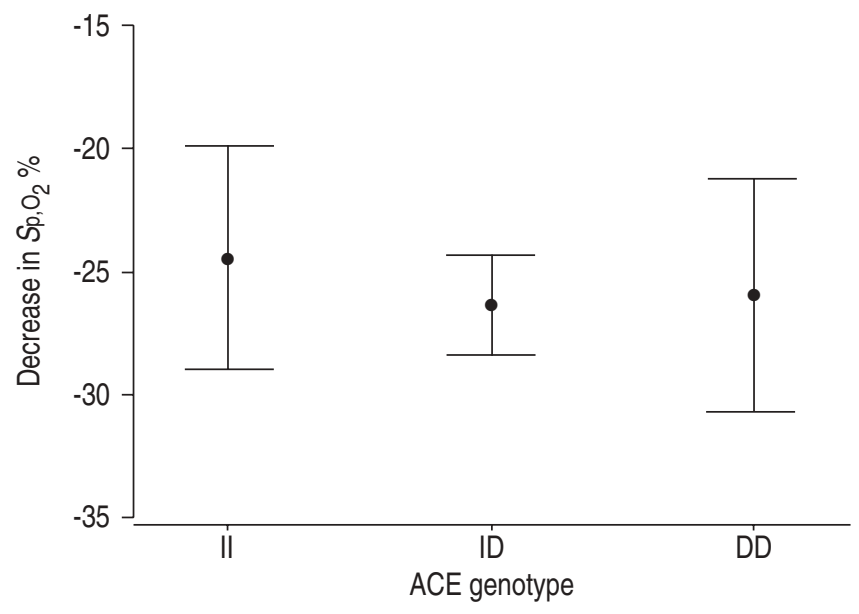

Fig. 3. - Mean \pm SEM per cent decreases in transcutaneous oxygen saturation $\left(\mathrm{S}_{\mathrm{p}, \mathrm{O}_{2}}\right)$ during exercise from the three angiotensin-converting enzyme (ACE) genotype groups (insertion homozygote (II), heterozygote (ID), deletion homozygote (DD)) as the subjects progressed from normoxia to hypoxia. There was no significant difference between the two homozygote groups.

The observed genotype dependency of the rise in $V^{\prime} \mathrm{E}$ (II $39.6 \pm 4.1 \%$ versus DD $28.4 \pm 2.2 \%, \mathrm{p}<0.02)$ is perhaps more reliant upon a genotype-related rise in RR $(20.9 \pm 5.6 \%$, $13.6 \pm 2.7 \%$ and $12.6 \pm 2.4 \%$, II, ID and DD, respectively) than $V \mathrm{~T}(15.0 \pm 3.1 \%, 12.9 \pm 2.1 \%$ and $13.7 \pm 2.4 \%$, II, ID and DD, respectively). However, neither were individually genotypedependent ( $\mathrm{p}=0.2$ and 0.7 , respectively).

Hypoxic ventilatory responses are mediated via the carotid body peripherally and medullary nuclei centrally, and either may play a role. Within the carotid body itself, responses to hypoxia are mediated by glomus type-I cells [20], which are known to express AT1 receptors [13]. The expression of these receptors is increased as part of the adaptive process to chronic hypoxia [12], consistent with the suggestion that local chemoreceptor RAS may play a role in mediating hypoxic ventilatory responses. However, the role of such glomus AT1 receptors in the transduction of responses to acute hypoxic exercise remain to be elucidated. The finding that putative lower RAS activity (the ACE II genotype) is associated with enhanced ventilatory response to acute hypoxic exercise suggest that, perhaps, local RAS activity is differentially regulated in acute and chronic hypoxic exposure. This concept is supported by a finding of better-preserved $\mathrm{Sa}, \mathrm{O}_{2}$ amongst those of II than DD genotype during rapid ascent to altitude, and the absence of such a finding when ascent is more gradual [21]. Such observations require further experimental evaluation. Alternatively, genotype-dependent alterations in central medullary-mediated signal transduction or hypoxic ventilatory responses may be important, given that AngII applied to the nuclei tractus solitarii of rats decreases phrenic nerve discharge frequency and amplitude [22]. Finally, a hypocapnoeic exercise model was used. The ventilatory response to hypoxia (acting at peripheral chemoreceptors) can be diminished by the associated hypocapnia. It is thus possible that the genotype is exerting its effect through alterations in hypocapnoeic receptor inhibition. Further studies are required to explore this hypothesis.

It should be noted that a significant genotype-dependent rise in ventilation with exposure to hypoxia in the absence of exercise was not identified. There may be several reasons for this. Firstly, the rise in $V^{\prime} \mathrm{E}$ with exposure to hypoxia though reasonable is small when compared with the degree of variability within the subject group (mean \pm SD $24.17 \pm 24.2$ ). 
Table 2. - Absolute values for metabolic variables at rest and exercise during normoxia and hypoxia

\begin{tabular}{|c|c|c|c|c|c|}
\hline & & II & ID & DD & p-value \\
\hline $\mathrm{F}: \mathrm{M}$ & & $14: 8$ & $30: 18$ & $16: 10$ & \\
\hline \multirow[t]{4}{*}{ Resting $V \mathrm{O}_{2} \mathrm{~L} \cdot \min ^{-1}$ BTPS } & Normoxic & $0.43 \pm 0.03$ & $0.40 \pm 0.02$ & $0.42 \pm 0.02$ & \\
\hline & Hypoxic & $0.41 \pm 0.03$ & $0.42 \pm 0.02$ & $0.40 \pm 0.01$ & \\
\hline & Change & $-0.02 \pm 0.01$ & $-0.01 \pm 0.01$ & $-0.017 \pm 0.01$ & \\
\hline & Change $\%$ & $-4.8 \pm 2.0$ & $6.05 \pm 3.4$ & $-2.7 \pm 3.1$ & 0.8 \\
\hline \multirow{4}{*}{ Exercise $V \mathrm{O}_{2} \mathrm{~L} \cdot \mathrm{min}^{-1} \mathrm{BTPS}$} & Normoxic & $1.62 \pm 0.13$ & $1.64 \pm 0.08$ & $1.66 \pm 0.09$ & \\
\hline & Hypoxic & $1.60 \pm 0.13$ & $1.64 \pm 0.07$ & $1.63 \pm 0.08$ & \\
\hline & Change & $-0.2 \pm 0.02$ & $0.006 \pm 0.02$ & $-0.03 \pm 0.05$ & \\
\hline & Change $\%$ & $-0.58 \pm 1.9$ & $1.4 \pm 1.5$ & $-0.8 \pm 1.1$ & 1.0 \\
\hline \multirow[t]{4}{*}{ Resting $V \mathrm{CO}_{2} \mathrm{~L} \cdot \mathrm{min}^{-1} \mathrm{BTPS}$} & Normoxic & $0.36 \pm 0.03$ & $0.33 \pm 0.02$ & $0.35 \pm 0.02$ & \\
\hline & Hypoxic & $0.43 \pm 0.04$ & $0.40 \pm 0.02$ & $0.40 \pm 0.02$ & \\
\hline & Change & $0.07 \pm 0.02$ & $0.07 \pm 0.01$ & $0.05 \pm 0.01$ & \\
\hline & Change \% & $16.0 \pm 4.4$ & $24.9 \pm 4.0$ & $16.1 \pm 3.5$ & 1.0 \\
\hline \multirow[t]{4}{*}{ Exercise $V \mathrm{CO}_{2} \mathrm{~L} \cdot \mathrm{min}^{-1}$ BTPS } & Normoxic & $1.37 \pm 1.0$ & $1.41 \pm 0.06$ & $1.44 \pm 0.06$ & \\
\hline & Hypoxic & $1.54 \pm 0.1$ & $1.57 \pm 0.07$ & $1.57 \pm 0.07$ & \\
\hline & Change & $-0.16 \pm 0.005$ & $0.16 \pm 0.02$ & $0.13 \pm 0.04$ & \\
\hline & Change $\%$ & $12.1 \% \pm 0.5$ & $11.5 \pm 1.5$ & $9.4 \pm 2.8$ & 0.5 \\
\hline \multirow[t]{4}{*}{ Resting $S \mathrm{p}, \mathrm{O}_{2} \%$} & Normoxic & $95.8 \pm 0.3$ & $92.7 \pm 3.0$ & $96.3 \pm 0.4$ & \\
\hline & Hypoxic & $85.3 \pm 0.04$ & $84.4 \pm 0.4$ & $83.9 \pm 1.0$ & \\
\hline & Change & $-10.8 \pm 0.8$ & $-11.5 \pm 0.4$ & $-11.7 \pm 0.7$ & \\
\hline & Change $\%$ & $-11.3 \pm 0.8$ & $-12.0 \pm 0.4$ & $-12.2 \pm 0.7$ & 0.4 \\
\hline \multirow[t]{4}{*}{ Exercise $S \mathrm{p}, \mathrm{O}_{2} \%$} & Normoxic & $94.2 \pm 0.3$ & $92.3 \pm 2.1$ & $95.3 \pm 0.3$ & \\
\hline & Hypoxic & $71.1 \pm 2.0$ & $69.1 \pm 1.0$ & $70.1 \pm 1.8$ & \\
\hline & Change & $-23.0 \pm 2.0$ & $-24.8 \pm 0.9$ & $-24.8 \pm 2.2$ & \\
\hline & Change $\%$ & $-24.5 \pm 2.1$ & $-26.3 \pm 1.0$ & $-25.9 \pm 2.1$ & 0.6 \\
\hline \multirow[t]{4}{*}{ Resting $\mathrm{ETCO}_{2} \mathrm{kPa}$} & Normoxic & $4.79 \pm 0.1$ & $4.91 \pm 0.06$ & $5.08 \pm 0.09$ & \\
\hline & Hypoxic & $4.38 \pm 0.1$ & $4.59 \pm 0.06$ & $4.74 \pm 0.08$ & \\
\hline & Change & $-0.41 \pm 0.09$ & $-0.32 \pm 0.05$ & $-0.32 \pm 0.05$ & \\
\hline & Change $\%$ & $-8.7 \pm 2.0$ & $-6.3 \pm 1.1$ & $-6.3 \pm 1.0$ & 0.3 \\
\hline \multirow[t]{4}{*}{ Exercise $\mathrm{ETCO}_{2} \mathrm{kPa}$} & Normoxic & $5.80 \pm 0.1$ & $5.80 \pm 0.07$ & $5.89 \pm 0.1$ & \\
\hline & Hypoxic & $4.70 \pm 4.7$ & $4.92 \pm 0.08$ & $5.00 \pm 0.1$ & \\
\hline & Change & $-1.08 \pm 0.1$ & $-0.89 \pm 0.05$ & $-0.89 \pm 0.07$ & \\
\hline & Change $\%$ & $-18.7 \pm 1.3$ & $-15.3 \pm 1.1$ & $-15.1 \pm 1.1$ & 0.05 \\
\hline
\end{tabular}

Data are presented as mean \pm SEM unless otherwise stated. F: female; M: male; BTPS: at body temperature and ambient pressure, and saturated with water vapour; $\mathrm{VO}_{2}$ : oxygen uptake; $V \mathrm{CO}_{2}$ : carbon dioxide production; $\mathrm{Sp}, \mathrm{O}_{2}$ : transcutaneous oxygen saturation; ETCO $\mathrm{ET}_{2}$ : end-tidal carbon dioxide Absolute changes and percentage changes for each angiotensin-converting enzyme genotype group (insertion homozygote (II), heterozygote (ID), deletion homozygote (DD)) are shown. p-values are for analysis of variance comparisons made on percentage changes between homozygote groups

As such, the study is underpowered to detect such a difference. This may be due to the degree of variability in resting ventilation in some subjects when connected to the circuit, despite a familiarisation period. Such variations were considerably reduced during exercise ( $V^{\prime} \mathrm{E} \quad 30.81 \pm 12.5$ ). Meanwhile, the substantial elevation in ventilatory response with exercise amplifies the power to detect between-group differences. As such, it may be that there is a real (but unidentified) association of genotype with basal HVR. Alternatively, it may be that the influence of genotype is only apparent during exercise; modulation of respiratory drive by $\mathrm{CO}_{2}$ is itself altered by exercise [23], and expiratory neurones (normally quiescent) may be active in projecting to the ventral medullary respiratory neurone group during exercise. Finally, ventilatory drive during exercise is closely related to $\mathrm{CO}_{2}$ burden. The presence of peripheral and central chemoreceptor RAS, the interaction between $\mathrm{CO}_{2}$ load and hypoxia in determining ventilator drive, and the role of both chemoreceptor locations in regulation of these responses, may account for an amplified response to hypoxia during exercise that is not seen at rest. The putative association of ACE genotype with resting hypoxic drive should be the subject of an appropriately powered prospective study.

It is unlikely that such ventilatory changes are the sole means through which high-altitude performance is enhanced, given the (albeit smaller) I allele excess identified among elite endurance athletes performing under normoxic conditions.
The substantial catabolic response seen with high-altitude exposure is associated with a reduction in muscle efficiency [24]. Mechanical efficiency improves more with training among II homozygotes [10], whilst the I allele is associated with training-related anabolism [25]. Such effects may improve hypoxic performance [27].

The fact that no evidence of allele codominance was detected also supports the presence of other mechanisms influencing altitude performance. Such exclusivity of association with homozygocity is not without precident, with the allele-specific dependence varying in different tissues. Thus, ACE activity is raised in monocytes only amongst those homozygous for the D allele [27].

Such genotype-dependent differences in hypoxic ventilatory drive may be expected to be associated with differences in $\mathrm{Sa}, \mathrm{O}_{2}$. Indeed, II genotype is associated with better-preserved oxygen saturation during rapid ascent to high altitude [21], while a similar preservation is noted amongst elite mountaineers [28], among whom the I-allele is over-represented [10]. Interestingly, however, such an effect was not observed in this study. This cannot be explained by there having been only a rise in dead-space ventilation, given that the fall in $\mathrm{ETCO}_{2}$ (reflecting alveolar ventilation) is genotype-dependent. It would seem similarly unlikely that acute increases in ventilation are being offset by an acute deterioration in ventilation/perfusion mismatch in association with the I allele, but this would appear to be the only explanation for a 
Table 3. - Absolute values for ventilatory variables at rest and exercise during normoxia and hypoxia

\begin{tabular}{|c|c|c|c|c|c|}
\hline & & II & ID & DD & p-value \\
\hline \multirow{5}{*}{ Resting $V^{\prime} \mathrm{E} \mathrm{L} \cdot \mathrm{min}^{-1}$} & & $14: 8$ & $30: 18$ & $16: 10$ & \\
\hline & Normoxic & $11.92 \pm 0.60$ & $11.15 \pm 0.50$ & $11.42 \pm 0.50$ & \\
\hline & Hypoxic & $15.52 \pm 1.90$ & $13.84 \pm 0.60$ & $13.28 \pm 0.59$ & \\
\hline & Change & $3.6 \pm 1.5$ & $2.7 \pm 0.5$ & $1.87 \pm 0.4$ & \\
\hline & Change $\%$ & $27.0 \pm 9.2$ & $26.5 \pm 4.3$ & $17.4 \pm 3.8$ & 0.3 \\
\hline \multirow[t]{4}{*}{ Exercise $V^{\prime} \mathrm{E} \mathrm{L} \cdot \mathrm{min}^{-1}$} & Normoxic & $33.87 \pm 2.3$ & $35.53 \pm 1.2$ & $36.06 \pm 1.40$ & \\
\hline & Hypoxic & $47.35 \pm 3.6$ & $45.40 \pm 1.7$ & $46.57 \pm 2.40$ & \\
\hline & Change & $13.48 \pm 1.7$ & $9.87 \pm 0.8$ & $10.51 \pm 1.10$ & \\
\hline & Change $\%$ & $39.6 \pm 4.1$ & $27.9 \pm 2.0$ & $28.4 \pm 2.2$ & 0.02 \\
\hline \multirow[t]{4}{*}{ Resting $V \mathrm{~T} \mathrm{~L}$} & Normoxic & $0.90 \pm 0.10$ & $0.79 \pm 0.05$ & $0.87 \pm 0.07$ & \\
\hline & Hypoxic & $1.07 \pm 0.20$ & $0.95 \pm 0.05$ & $1.00 \pm 0.08$ & \\
\hline & Change & $0.17 \pm 0.10$ & $0.15 \pm 0.30$ & $0.14 \pm 0.06$ & \\
\hline & Change $\%$ & $15.8 \pm 3.2$ & $23.0 \pm 3.8$ & $18.2 \pm 6.4$ & 0.8 \\
\hline \multirow[t]{4}{*}{ Exercise $V \mathrm{~T} \mathrm{~L}$} & Normoxic & $1.77 \pm 0.10$ & $1.78 \pm 0.09$ & $1.80 \pm 0.10$ & \\
\hline & Hypoxic & $2.04 \pm 0.20$ & $2.01 \pm 0.10$ & $2.03 \pm 0.10$ & \\
\hline & Change & $0.27 \pm 0.07$ & $0.23 \pm 0.04$ & $0.24 \pm 0.04$ & \\
\hline & Change $\%$ & $15.0 \pm 3.1$ & $12.9 \pm 2.1$ & $13.7 \pm 2.4$ & 0.7 \\
\hline \multirow[t]{4}{*}{ Resting RR breaths $\cdot \min ^{-1}$} & Normoxic & $14.75 \pm 0.9$ & $15.26 \pm 0.60$ & $14.79 \pm 0.80$ & \\
\hline & Hypoxic & $16.05 \pm 0.8$ & $15.77 \pm 0.60$ & $14.54 \pm 1.00$ & \\
\hline & Change & $1.29 \pm 0.9$ & $0.5 \pm 0.6$ & $-0.25 \pm 0.50$ & \\
\hline & Change \% & $11.0 \pm 5.7$ & $4.8 \pm 3.7$ & $-1.7 \pm 3.6$ & 0.06 \\
\hline \multirow{4}{*}{ Exercise RR breaths $\cdot \mathrm{min}^{-1}$} & Normoxic & $19.84 \pm 0.80$ & $21.14 \pm 0.80$ & $21.52 \pm 1.20$ & \\
\hline & Hypoxic & $23.74 \pm 1.00$ & $23.89 \pm 0.90$ & $24.10 \pm 1.30$ & \\
\hline & Change & $3.89 \pm 0.90$ & $2.74 \pm 0.50$ & $2.57 \pm 0.50$ & \\
\hline & Change $\%$ & $20.9 \pm 5.6$ & $13.6 \pm 2.7$ & $12.6 \pm 2.4$ & 0.2 \\
\hline
\end{tabular}

Data are presented as mean \pm SEM unless otherwise stated. F: female; M: male; $V^{\prime} E$ : minute ventilation; $V \mathrm{~T}$ : tidal volume; RR: respiratory rate. Absolute changes and percentage changes for each genotype group (insertion homozygote (II), heterozygote (ID), deletion homozygote (DD)). p-values are for analysis of variance comparisons made on percentage changes between homozygote groups.

deterioration in gas exchange in the face of an increase in alveolar oxygen tension. Hypoxia increases pulmonary vascular ACE expression [29, 30], and both ACE inhibitors [31] and AT1-receptor antagonists [32] attenuate the hypoxic pulmonary vasoconstrictor response [33]. It is therefore possible that the I allele is associated with a deterioration in ventilation/perfusion matching in the face of hypoxia, via reduced regional vasoconstriction.

It should be noted that this study applied only brief normobaric hypoxia. Different levels of hypoxaemia at different barometric pressures, and overacclimatisation periods to chronic hypoxaemia should be studied to simulate the "field effect" of progressive ascent. In addition, although poikilocapnic ventilatory responses are indeed closer to real life situations, the use of isocapnoeic protocols may better help dissect the mechanism.

In addition, only healthy White subjects were studied, and the study should be repeated among different racial groups and those of different ages. The sample size was insufficient to prove conclusively whether respiratory rate or tidal volume were predominantly dependent upon genotype, and this should be addressed in larger studies. Finally, mechanistic studies are required in order to determine the role of central versus peripheral chemoreceptor responses. Such studies should include assessment of isocapnoeic hypoxic ventilation. Nonetheless, these data demonstrate an association of angiotensin-converting enzyme genotype with differences in the exertional hypoxic ventilatory response. Such data have implications not only for mountaineers, but also for patients suffering a wide variety of heart and lung disease that are associated with hypoxemia. Further study is warranted, given the potential therapeutic roles for the widely available antagonists of the renin-angiotensin system.

Acknowledgements. The authors would like to thank the volunteers who took part in this study.

\section{References}

1. Rupert JL, Hochachka PW. The evidence for hereditary factors contributing to high altitude adaptation in Andean natives: a review. High Alt Med Biol 2001; 2: 235-256.

2. Danser AH, Schalekamp MA, Bax WA, et al. Angiotensin converting enzyme in the human heart. Effect of the deletion/ insertion polymorphism. Circulation 1995; 92: 1387-1388.

3. Reneland R, Haenni A, Andersson PE, Andren B, Lithell H. Skeletal muscle angiotensin-converting enzyme and its relationship to blood pressure in primary hypertension and healthy elderly men. Blood Press 1999; 8: 16-22.

4. Yosipov IV, Dipp S, El-Dahr SS. Ontogeny of somatic angiotensin-converting enzyme. Hypertension 1994; 23: 369374.

5. Kanazawa H, Okamoto T, Hirata K, Yoshikawa J. Deletion polymorphisms in the angiotensin converting enzyme gene are associated with pulmonary hypertension evoked by exercise challenge in patients with chronic obstructive pulmonary disease. Am J Respir Crit Care Med 2000; 162: $1235-1238$.

6. Rigat B, Hubert C, Alhenc-Gelas F, Cambien F, Corvol P, Soubrier F. An insertion/deletion polymorphism in the angiotensin-1-converting enzyme gene accounting for half the variance of serum enzyme levels. J Clin Invest 1990; 86: 1343-1346.

7. Gayagay G, Yu B, Hambly B, et al. Elite endurance athletes and the ACE I allele--the role of genes in athletic performance. Hum Genet 1998; 103: 48-50.

8. Myerson S, Hemingway H, Budget R, Martin J, Humphries $\mathrm{S}$, Montgomery H. Human angiotensin I-converting enzyme gene and endurance performance. J Appl Physiol 1999; 87: $1313-1316$.

9. Woods DR, Brull D, Montgomery HE. Endurance and the ACE I/D polymorphism. Sci Prog 2002; 83: 317-336.

10. Williams AG, Rayson MP, Jubb M, et al. The ACE gene and muscle performance. Nature 2000; 403: 614.

11. Montgomery HE, Marshall RM, Hemingway $\mathrm{H}$, et al. 
Human gene for physical performance. Nature 1998; 393: 221-222.

12. Leung PS, Lam SY, Fung ML. Chronic hypoxia upregulates the expression and function of AT(1) receptor in rat carotid body. J Endocrinol 2000; 167: 517-524.

13. Allen AM. Angiotensin AT1 receptor-mediated excitation of rat carotid body chemoreceptor afferent activity. $J$ Physiol 1998; 510: 773-781.

14. Weil JV, Byrne-Quinn E, Sodal IE, et al. Hypoxic ventilatory drive in normal man. J Clin Invest 1970; 49: 1061-1072.

15. Collins DD, Scoggin CH, Zwillich CW, Weil JV. Hereditary aspects of decreased hypoxic response. J Clin Invest 1978; 62: $105-110$.

16. Kawakami Y, Yamamoto H, Yoshikawa T, Shida A. Chemical and behavioral control of breathing in adult twins. Am Rev Respir Dis 1984; 129: 703-707.

17. Redline S, Leitner J, Arnold J, Tishler PV, Altose MD. Ventilatory-control abnormalities in familial sleep apnea Am J Respir Crit Care Med 1997; 156: 155-160.

18. Bolla MK, Haddad L, Humphries SE, Winder AF, Day INM. A method for determination of hundreds of APOE genotypes utilising highly simplified, optimised protocols and restriction digestion analysis by microtitre array diagonal gel electrophoresis (MADGE). Clin Chem 1995; 41: 1599-1604.

19. O'Dell, Humphries SE, Day INM. Rapid methods for population-scale analysis for gene polymorphisms: the ACE gene as an example. Br Heart $J$ 1995; 73: 368-371.

20. Bisgard GE. Carotid body mechanisms in acclimatization to hypoxia. Respir Physiol 2000; 121: 237-246.

21. Woods DR, Pollard A, Collier DJ, et al. The ACE genotype and oxygen saturation at high altitude. Am J Respir Crit Care Med 2002; 166: 362-366.

22. Paton JF, Kasparov S. Differential effects of angiotensin II on cardiorespiratory reflexes mediated by nucleus tractus solitarii - a microinjection study in the rat. J Physiol 1999; 521: 213-225.

23. Turner DL, Sumners DP. Associative conditioning of the exercise ventilatory response in humans. Respir Physiol Neurobiol 2002; 132: 159-168.

24. Hoppeler H, Howald H, Cerretelli P. Human muscle structure after exposure to extreme altitude. Experientia 1990; 46: 1185-1187.

25. Montgomery H, Clarkson P, Barnard M, et al. Angiotensinconverting-enzyme gene insertion/deletion polymorphism and response to physical training. Lancet 1999; 353: 541-545.

26. Mancini DM. Pulmonary factors limiting exercise capacity in patients with heart failure. Prog Cardiovasc Dis 1995; 37: 261-269.

27. Costerousse $\mathrm{O}$, Allegrini $\mathrm{J}$, Lopez $\mathrm{M}$, Alhenc-Gelas $\mathrm{F}$. Angiotensin-I converting enzyme in human circulating mononuclear cells: genetic polymorphism of expression in T-lymphocytes. Biochem J 1993; 290: 33-40.

28. Oelz O, Howald H, Di Prampero PE, et al. Physiological profile of world-class high-altitude climbers. $J$ Appl Physiol 1986; 60: 1734-1742.

29. Morrell NW, Atochina EN, Morris KG, Danilov SM, Stenmark KR. Angiotensin converting enzyme expression is increased in small pulmonary arteries of rats with hypoxiainduced pulmonary hypertension. J Clin Invest 1995; 96: $1823-1833$.

30. King SJ, Booyse FM, Lin PH, Taylor M, Narkates AJ, Oparil S. Hypoxia stimulates endothelial cell angiotensinconverting enzyme antigen synthesis. Am J Physiol 1989; 256: C1231-C1238.

31. Cargill RI, Lipworth BJ. Lisinopril attenuates acute hypoxic pulmonary vasoconstriction in humans. Chest 1996; 109: $424-429$.

32. Kiely DG, Cargill RI, Lipworth BJ. Angiotensin II receptor blockade and effects on pulmonary hemodynamics and hypoxic pulmonary vasoconstriction in humans. Chest 1996 ; 110: 698-703.

33. Nong Z, Stassen JM, Moons L, Collen D, Janssens S. Inhibition of tissue angiotensin-converting enzyme with quinapril reduces hypoxic pulmonary hypertension and pulmonary vascular remodeling. Circulation 1996; 94: 1941-1947. 